\title{
News Sentiment and Its Effect on Price Momentum and Sentiment Momentum
}

\author{
Shu-Ling Chang, Long-Jainn Hwang, Chun-An Li, and Min-Zhi Yao
}

\begin{abstract}
The research indicates that Taiwan stock market in short-term would contain price momentum and sentiment momentum during 2001-2010. As for the long term, it would contain price contrarian effect. Furthermore, through the combination of good, bad news, price momentum, and sentiment momentum, it shows that short days accumulation of news have great effects on the short-term price momentum and the effects are more significant or reversed. However, the long-term price contrarian momentum shows negative correlation. It is extent of fluctuation would change with the collocation of good, bad news. In contrast, short-term sentiment momentum shows positive correlation and the result shows positive effect. Long-term sentiment momentum will also be influenced by the accumulation of news. The analysis of the result shows that it would be significant. And these positive and negative significances need to follow with different combination of investment portfolios.
\end{abstract}

Index Terms-Price momentum, sentiment momentum, news.

\section{INTRODUCTION}

The purpose of this paper is to test if there exists price momentum or sentiment momentum in Taiwan stock market in short-term and long-term, and more importantly, to investigate the impact of good, bad news on price momentum and sentiment momentum.

In recent years, the market efficient hypothesis developed by [1] has been challenged due to the appearance of many anomalies (e.g. January effect, price-earnings effect, and overreaction). Many previous studies have shown that trading strategy can obtain abnormal return. Ref. [2], [3] argue that stock prices overreact to information, suggesting that contrarian strategies (buying past losers and selling past winners) achieve abnormal returns. However, the analysis results of the DeBondt and Thaler are still being debated. Ref. [4] documents momentum strategies which buy stocks that have performed well in the past and sell stocks that have performed poorly in the past generate significant positive returns over 3-month to 12-month holding periods. Therefore, the first objective of this paper is to test whether or not there exist price momentum in Taiwan stock market.

Manuscript received October 5, 2017; revised December 11, 2017.

Shu-Ling Chang is with Department of Finance, National Yunlin University of Science and Technology and Department of International Business, Southern Taiwan University of Science and Technology, Taiwan (e-mail: D10124006@yuntech.edu.tw).

Long-Jainn Hwang is with Department of Marketing and Distribution Management, WuFeng University, Taiwan (e-mail: ljhwang@wfu.edu.tw).

Chun-An Li and Min-Zhi Yao are with Department of Finance, National Yunlin University of Science and Technology, Taiwan (e-mail: liica@yuntech.edu.tw, g9924724@yuntech.edu.tw).
Meanwhile, as human beings, we all experience a wide range of emotions (see [5], [6]). Also, many scholars in psychology usually support the analysis that emotions have significant impact on decision making (see [7], [8]). Since an individual's mood state can affect judgment and decision making, emotions therefore correlate accordingly with stock returns (see [6], [9], and [10]). Ref. [11] present how investor sentiment affects the cross-section of stock returns. Hence, the second objective of this paper is to test whether there exist sentiment momentum in Taiwan stock market.

Further, [12] establish a model of underreaction, overeeaction, sentiment, and momentum. Their framework indicates that news play an important part of the model. Proposition 1 of [12] argue that "in response to good news there is continued upward momentum in prices least $j$ periods....". Taiwan stock market is a shallow-plate market, any good or bad news associated with the companies will affect the performance of stock returns. Hence, we consider how the variation of news, good news or bad news, have an effect on price momentum and sentiment momentum in Taiwan stock market. Does accumulation of news, long-term or short-term, has effects on the price momentum and sentiment momentum? This will be the third objective of current paper.

This article address these questions by examining the weekly trading information of public listed companies traded on the Taiwan Stock Exchange from 2001 to 2010. The research indicates that Taiwan stock market in short-term would contain price momentum and sentiment momentum during 2001-2010. As for the long-term, it would contain price contrarian effect. Furthermore, through the combination of good, bad news, price momentum, and sentiment momentum, it shows that short days accumulation of news have great effects on the short-term price momentum and the effects are more significant or reversed. However, the long-term price contrarian momentum shows negative correlation. The results would change with the collocation of good, bad news. In contrast, short-term sentiment momentum shows positive correlation and the result shows positive effect. Long-term sentiment momentum will also be influenced by the accumulation of news. The analysis of the result shows that it would be significant. And these positive and negative significances need to follow with different combination of investment portfolios.

The main contribution of this article is that we are the first to investigate the relationship between good, bad news and price momentum, and also sentiment momentum. We find that differ good news from bad news is helpful to understand the effect of news on price momentum, and also sentiment 
momentum.

The remainder of the paper is organized as follows. Section II describes the theoretical background. Section III explains data and methodology. Section IV presents the empirical results and Section IV concludes and discusses the further research.

\section{THEORETICAL BACKGROUND}

\section{A. Price Momentum}

The phenomenon of price momentum has been documented in several studies. Ref. [13] probably was the first article to use similar strategy of price momentum. He claimed that relative strength strategies that buy the stocks that have returns above the past twenty-seven weeks average returns and hold it for a period will get significantly abnormal return.

Ref. [2] provided empirical evidence to support overreaction hypothesis based on CRSP monthly return data from 1926 to 1982 . They used non-overlapping three-year periods to calculate cumulative excess return and rank so as to form the winner and loser portfolio. They found that the losing stocks had earned about $25 \%$ more than the winners, even though the latter are significantly more risky. This result indicated that stock price may inverse three years later.

Ref. [4] analysis the monthly data of NYSE and AMEX stocks market from 1965 to 1989 . Using both formation and holding periods of $3,6,9,12$ months to create 16 portfolios, they documents that strategies which buy stocks that have performed well in the past and sell stocks that have performed poorly in the past generate significant positive returns over 3to 12 -month holding periods.

Combining contrarian and momentum investment strategies, [14] build a model based on representativeness hypothesis to explain investors' reaction to a sequence of good or bad news. They claim that investors will suspect the new information and react not enough to the unexpected news But after a series of announcements of good news, the investor becomes overly optimistic that future news announcements will also be good and hence overreacts, sending the stock price to unduly high levels. But the stock price will not be permanently overestimated, the stock price will be reversed eventually.

Ref. [12] model a market populated by two groups of boundedly rational agents: newswatchers (focusing fundamental analysis) and momentum traders (focusing technical analysis). Each newswatcher observes some private information and trade, and the momentum traders trade according to the pervious stock price. If information diffuses gradually across the population, prices underreact in the short run. The underreaction means that the momentum traders can profit by trend-chasing. However, if they can only implement simple strategies, their attempts at arbitrage must certainly lead to overreaction at long horizons.

Ref. [15] investigate the profitability of momentum investment strategy in six Asian stock markets including Taiwan. They find that unrestricted momentum investment strategies do not yield significant momentum profits. However, the excess return to winner-loser portfolio in

\section{Taiwan market is highest.}

\section{B. Sentiment Momentum}

Sentiment, broadly defined, refers to whether an individual, for whatever extraneous reason, feels excessively optimistic or pessimistic about a situation. A large body of the psychology literature finds that peoples' current sentiment affects their judgment of future events. For example, Ref. [16] show that people who read sad newspaper articles subsequently view various causes of death, such as disease, etc., as more likely than people who read pleasant newspaper articles. In general, the evidence indicates that people with positive sentiment make optimistic judgments and choices, whereas people with negative sentiment make pessimistic ones ([17], [18], among others).

Ref. [14] states that conservatism bias lead to the underreaction and overreaction. Ref. [19] also constructs a model of investor sentiment aimed at reconciling the empirical findings of overreaction and underreaction. They also use concepts from psychology to support their framework. Ref. [20], who had established a three-region interaction model based on level of sentiment, have found that using the turnover rate to examine the existential circumstances of irrational investors offers a good explanatory power.

Although sentiment is a conceptual concept, many investor sentiment measures have been identified in the academic literature and in the popular press. These indirect index include put-call ratio [21], net cash flow into mutual funds [22], Barron's Confidence Index [23], Risk Appetite Index [24], issuance percentage [11], closed-end fund discount [11], VIX-Investor Fear Gauge [25], average first-day returns on IPOs [11], [26].

Ref. [9] examine several proxies for investor sentiment including closed-end fund discount, the net flow of funds into mutual funds, the percentage of mutual fund assets held as cash, and the number of IPOs during the month, the first-day return on IPOs during the month, and the bull-bear spread and its relation to near-term stock market returns. They find that many commonly cited indirect measures of sentiment are related to direct measures (surveys) of investor sentiment.

Ref. [27] indicated that if investors gain from previous trading, than they tend to be overconfident. Overconfident investors will trade too frequently, that is, the gains overconfident investors realize through trade will be less than they anticipate and may not even offset the costs of trading. Ref. [28] found that the participation of overconfident traders in the market leads to higher transactions volume. Ref. [20] indicate that when the motion is high in the market, the noise-trader will try to hold more equities, the trading volume will increase and the turnover rate will be high. Therefore, they suggest that turnover, or more generally liquidity, can serve as a sentiment index. Ref. [11] also use turnover as a sentiment index to study how investor sentiment affects the cross-section of stock returns. Because trading volume is the consequence of reflecting investor' future anticipation, [10] found that trading volume is a good indicator of investor sentiment. Using turnover rate, [29] investigates whether and how futures market sentiment and stock market returns heterogeneously affect the trading activities of institutional 
investors in the spot market in Taiwan. Therefore, we will use turnover rate as the proxy of investor sentiment.

\section{DATA AND METHODOLOGY}

The Taiwan stock market was established in 1962. However, Market Observation Post System provided by Taiwan Stock Exchange Corporation that offer good (bad) news of public listed companies is available for public until 2002. The study thus chose the period from 2001 to 2010 and adopted the weekly trading information on public listed companies traded at the Taiwan Stock Exchange to conduct an empirical analysis. Companies that have been delisted or issued a temporary cease trade order were included in the portfolio as the missing data may have an influence on the calculation of returns of formation periods and holding periods. At the beginning, 638 companies were included in the sample and the number was increased to 790 at the end of the study period. Data such as closing price, turnover rate, and market return were collected from the Taiwan Economic Journal (TEJ). News about company is from Market Observation Post System provided by Taiwan Stock Exchange Corporation.

The study process was primarily comprised of four steps. First, we test whether there exist price momentum or reverse in Taiwan stock market. The method proposed by [26] was used to divide the cumulative return of the individual companies over the past 3, 6, 12, 24, and 52 weeks into five different formation periods. The cumulative weekly average returns were calculated and ranked with overlapping holding periods with equal weights to establish the momentum strategy, buying past winners R5 (top 20\%) and selling past losers R1 (bottom 20\%), and holding it for 3, 6, 12, 24, and 52 weeks to examine whether price momentum or reverse exists in the Taiwan stock market.

Second, we examined the connection of good, bad news and price momentum. Based on the database of Market Observation Post System provided by Taiwan Stock Exchange Corporation, we collected all news of public listed companies from 2001 to 2010 . The news included investment performance, operating management, personnel changes, re-elect board members, and all other associated events that may inference the stock price of the company. The news is classified into good news and bad news when its influence is obvious. If the news is neutral or not so clear, then it will be excluded. Good news will get positive one point and bad news get negative one point with weekly based to calculate the summation. We argue that price momentum will be different according to the accumulation of news. We use two steps to group portfolios. First, the cumulative weekly average returns were calculated and ranked again. Second, the group of winners R5 (top 20\%) are divided into five portfolios: from wn1 to wn5. The wn1 portfolio is those winners that its accumulation of news is positive and in the first half (top $50 \%$ ). The wn2 portfolio is those winners that its accumulation of news is positive and in the second half (bottom 50\%). The wn3 portfolio is those winners without any news. The wn4 portfolio is those winners that its accumulation of news is negative and in the first half (top $50 \%$ ). The wn5 portfolio is those winners that its accumulation of news is negative and in the first half (bottom $50 \%$ ). Use the same setting, the group of losers R1 (bottom $20 \%$ ) are also divided into five portfolios: from $\ln 1$ to $\ln 5$. The $\ln 1$ portfolio is those losers that its accumulation of news is positive and in the first half (top 50\%). The $\ln 2$ portfolio is those losers that its accumulation of news is positive and in the second half (bottom 50\%). The $\ln 3$ portfolio is those losers without any news. The $\ln 4$ portfolio is those losers that its accumulation of news is negative and in the first half (top $50 \%$ ). The $\ln 5$ portfolio is those losers that its accumulation of news is negative and in the first half (bottom 50\%). Next, we use only two portfolio strategies to test the connection between accumulation of news and price momentum: (1) both holding periods and formation periods are 3 weeks; (2) both holding periods and formation periods are 52 weeks. We will use 3 weeks as short-run and 52 weeks as long-run. Combining these two portfolio strategies with accumulation of news for 3 weeks and 52 weeks, we can investigate if shortand long-term accumulation of news has effects on short- and long-term price momentum.

Third, a similar procedure as the first part is set to test whether there do exist sentiment momentum in Taiwan stock market. Following [20] and [11], we use turnover rate to proxy sentiment. Turnover is the ratio of reported trading volume to average outstanding shares. Again, the cumulative weekly turnover rate were calculated with overlapping holding periods to establish the sentiment momentum strategy, buying past winners S5 (top 20\% turnover rate) and selling past losers S1 (bottom 20\% turnover rate), and holding it for 3, $6,12,24$, and 52 weeks to examine whether sentiment momentum strategy do exist in the Taiwan stock market.

Finally, the forth part of study process is to examine the connection of good, bad news and sentiment momentum. We use almost the same procedures as second part but replace cumulative weekly average returns with cumulative weekly turnover rate to proxy sentiment momentum.

\section{EMPIRICAL RESULTS}

\section{A. Testing Price Momentum and Reverse}

Twenty-five strategies are established based on equally weighted cumulative returns over the formation period and holding period. Table I shows that most short-term investment strategies generate a positive return, among them, [3, 3] (3-week formation period / 3-week holding period) has the highest return of R5-R1 (0.73\%). However, most long-term investment strategies generate a negative return, among them, [52/52] (52-week formation period/52-week holding period) has the highest statistical significance and lowest return of R5-R1 (-5.1\%). These results support the previous research conclusions that there are short-term of price momentum and long-term price reverse in the Taiwan stock market.

\section{B. Testing the Connection between Good, Bad News and Price Momentum}

In this section, we further test how the short- and long-term accumulation of news affects short-term of price momentum and long-term price reverse. Table II provides the connection between short-term accumulation of news and short-term price momentum. As shown in Table II, the momentum 
strategy that portfolio of buying wn3 and selling $\ln 1$, the return of (R-L) is $1.04 \%$ which is positive of $5 \%$ statistical significance. Also in the portfolio of buying wn3 and selling $\ln 2$, the return of (R-L) is $1.2 \%$ which is positive of $5 \%$ statistical significance. Compared with the return of investment strategies of 3-week formation period and 3-week holding period is $0.73 \%$ in the Table I, we can inference that when the winners with no news but the loser with short-turn accumulation of good news the returns of losers are lower since (R-L) is higher $(1.04 \%)$ than $0.73 \%$.

TABLE I: PRICE MOMENTUM AND REVERSE

\begin{tabular}{ccccccc}
\hline \multirow{2}{*}{$\begin{array}{c}\text { Formation } \\
\text { Periods }\end{array}$} & \multirow{2}{*}{ Portfolios } & \multicolumn{6}{c}{ Holding Periods } \\
\cline { 3 - 7 } 3 & R5-R1 & 0.73 & 0.21 & -0.04 & -1.2 & -1.11 \\
& & $(1.5)$ & $(0.27)$ & $(-0.03)$ & $(-0.63)$ & $(-0.45)$ \\
\multirow{2}{*}{6} & \multirow{2}{*}{ R5-R1 } & 0.16 & -0.4 & -1.08 & -2.79 & -3.83 \\
& & $(0.31)$ & $(-0.53)$ & $(-0.89)$ & $(-1.43)$ & $(-1.51)$ \\
12 & \multirow{2}{*}{ R5-R1 } & -0.29 & -1.05 & -1.97 & -4.46 & -6.38 \\
& & $(-0.57)$ & $(-1.37)$ & $(-1.63)$ & $\left(-2.3^{* *}\right)$ & $\left(-2.4^{* *}\right)$ \\
24 & \multirow{2}{*}{ R5-R1 } & -0.85 & -1.83 & -3.14 & -4.56 & -9.01 \\
& & $(-1.7 *)$ & $\left(-2.3^{* *}\right)$ & $(-2.4 * *)$ & $\left(-2.2^{* *}\right)$ & $\left(-3.4^{* * *}\right)$ \\
52 & \multirow{2}{*}{ R5-R1 } & -0.68 & -1.71 & -3.72 & -7.61 & -13.9 \\
& & $(-1.3)$ & $(-2.1 * *)$ & $\left(-2.9^{* * *}\right)$ & $\left(-3.7^{* * *}\right)$ & $\left(-5.1^{* * *}\right)$ \\
\hline
\end{tabular}

In the portfolio of buying wn3 and selling $\ln 5$, the return of (R-L) is $1.37 \%$ which is positive of $5 \%$ statistical significance. Compared with the return of investment strategies of 3-week formation period and 3-week holding period is $0.73 \%$ in the Table I, we can inference that when the winners with no news but the loser with short-turn accumulation of bad news the returns of losers are become even lower since (R-L) is more higher $(1.37 \%)$ than $0.73 \%$.

TABLE II: CONNECTION BETWEEN SHORT-TERM ACCUMULATION OF NewS AND SHORT-TERM PRICE MOMENTUM

\begin{tabular}{|c|c|c|c|c|c|}
\hline \multirow{2}{*}{$\begin{array}{c}\text { Investment } \\
\text { Strategy }\end{array}$} & \multicolumn{5}{|c|}{ Short Sell } \\
\hline & $\ln 1$ & $\ln 2$ & $\ln 3$ & $\ln 4$ & $\ln 5$ \\
\hline \multirow[t]{6}{*}{ wn1 } & 0.18 & 0.35 & -0.15 & -0.17 & 0.52 \\
\hline & $(0.35)$ & $(0.56)$ & $(-0.30)$ & $(-0.29)$ & $(0.86)$ \\
\hline & 0.3 & 0.46 & -0.03 & -0.06 & 0.63 \\
\hline & $(0.55)$ & $(0.72)$ & $(-0.06)$ & $(-0.10)$ & $(1.01)$ \\
\hline & 1.04 & 1.2 & 0.7 & 0.68 & 1.37 \\
\hline & $\left(2.12^{* *}\right)$ & $\left(2.04^{* *}\right)$ & (1.51) & (1.17) & $(2.37 * *)$ \\
\hline \multirow[t]{2}{*}{ wn4 } & -0.64 & -0.48 & -0.97 & -1.00 & -0.31 \\
\hline & $(-1.11)$ & $(-0.72)$ & $\left(-1.73^{*}\right)$ & $(-1.52)$ & $(-0.47)$ \\
\hline \multirow[t]{2}{*}{ wn5 } & 0.17 & 0.33 & -0.16 & -0.19 & 0.51 \\
\hline & $(0.29)$ & $(0.49)$ & $(-0.28)$ & $(-0.28)$ & $(0.76)$ \\
\hline
\end{tabular}

In the portfolio of buying wn 4 and selling $\ln 3$, the return of (R-L) is $-0.97 \%$ which is negative of $10 \%$ statistical significance. Compared with the return of investment strategies of 3-week formation period and 3-week holding period is $0.73 \%$ in the Table I, we can inference that when the loser with no news but the winner with short-turn accumulation of bad news, the returns of winners are become lower and this means that price reverse occur.

Table III provides the connection between long-term accumulation of news and short-term price momentum. As shown in Table III, in portfolio of buying wn3 and selling $\ln 1$, buying wn3 and selling $\ln 2$, the returns of (R-L) are $1.12 \%$ and $1.12 \%$ which are both $5 \%$ statistical significance. The results show indicate that when the winners with no news but the losers with long-turn accumulation of good news, the returns of price momentum portfolio (R-L) will be higher and significant. This indicates that long-turn accumulation of good news is not helpful for losers to push ahead the stock prices. Also in portfolio of buying wn 4 and selling $\ln 1$, buying wn4 and selling $\ln 2$, the returns of (R-L) are both positive and significant. This indicates that long-turn accumulation of bad news can't reduce the stock prices of winners. In other words, when the losers are with long-turn accumulation of good news their stock prices are over-estimated, and when the winners are with long-turn accumulation of bad news their stock prices are under-estimated.

TABLE III: CONNECTION BETWEEN LONG-TERM ACCUMULATION OF News AND SHORT-TERM PRICE MOMENTUM

\begin{tabular}{|c|c|c|c|c|c|c|}
\hline \multirow{2}{*}{\multicolumn{2}{|c|}{$\begin{array}{c}\text { Investment } \\
\text { Strategy }\end{array}$}} & \multicolumn{5}{|c|}{ Short Sell } \\
\hline & & $\ln 1$ & $\ln 2$ & $\ln 3$ & $\ln 4$ & $\ln 5$ \\
\hline \multirow{5}{*}{ Buy } & wn1 & $\begin{array}{c}0.58 \\
(1.29)\end{array}$ & $\begin{array}{c}0.57 \\
(1.25)\end{array}$ & $\begin{array}{c}0.14 \\
(0.30)\end{array}$ & $\begin{array}{c}-0.29 \\
(-0.52)\end{array}$ & $\begin{array}{c}0.06 \\
(0.11)\end{array}$ \\
\hline & wn2 & $\begin{array}{c}0.55 \\
(1.21)\end{array}$ & $\begin{array}{c}055 \\
(1.17)\end{array}$ & $\begin{array}{c}0.11 \\
(0.24)\end{array}$ & $\begin{array}{l}-0.31 \\
(-0.55)\end{array}$ & $\begin{array}{c}0.04 \\
(0.67)\end{array}$ \\
\hline & win3 & $\begin{array}{c}1.12 \\
(2.41 * *)\end{array}$ & $\begin{array}{c}1.12 \\
(2.34 * *)\end{array}$ & $\begin{array}{c}0.68 \\
(1.43)\end{array}$ & $\begin{array}{c}0.26 \\
(0.46)\end{array}$ & $\begin{array}{c}0.61 \\
(1.06)\end{array}$ \\
\hline & wn4 & $\begin{array}{c}1.11 \\
(1.99 * *)\end{array}$ & $\begin{array}{c}1.11 \\
(1.95)\end{array}$ & $\begin{array}{c}0.68 \\
(1.18)\end{array}$ & $\begin{array}{c}0.25 \\
(0.39)\end{array}$ & $\begin{array}{c}0.6 \\
(0.92)\end{array}$ \\
\hline & wn5 & $\begin{array}{c}0.51 \\
(0.92)\end{array}$ & $\begin{array}{l}0.51 \\
(0.9)\end{array}$ & $\begin{array}{c}0.07 \\
(0.13)\end{array}$ & $\begin{array}{l}-0.35 \\
(-0.55)\end{array}$ & $\begin{array}{l}-0.01 \\
(-0.01)\end{array}$ \\
\hline
\end{tabular}

Table IV provides the connection between short-term accumulation of news and long-term price momentum. As shown in Table IV, under the condition of both holding periods and formation periods are 52 weeks and accumulation of news is 3 weeks, most of the returns of price momentum portfolio are negative. Compared with the return (R5-R1) of investment strategies of 52-week formation period and 52 -week holding period is $-13.9 \%$ in the Table I, we can conjecture that the existence of long-term price reverse will not affected by short-turn accumulation of news. Also as shown in Table $\mathrm{V}$, the result of the existence of long-term price reverse will not affected by accumulation of news still hold in the long-turn accumulation of news.

\section{Testing Sentiment Momentum}

Table VI present the analysis of testing sentiment momentum. As shown in Table VI, only [3,3] (3-week formation period / 3 -week holding period) has significant positive return of S5-S1 (0.69\%). Although others investment strategies also generate positive returns but are not significant. This conclusion supports that there is short-term of sentiment momentum but there is no long-term sentiment momentum in the Taiwan stock market.

\section{Testing the Connection between Good, Bad News and Sentiment Momentum}

Table VII provides the connection between short-term accumulation of news and short-term sentiment momentum. As shown in Table VII, the returns of sentiment momentum strategy in the upper-left and upper-right of the table VII are all positive and mostly significant. The upper-left of the table 
VII, including (wn1, $\ln 1),(w n 1, \ln 2),(w n 2, \ln 1)$, and (wn2, $\ln 2$ ), represent that both winners and losers portfolios are with short-turn accumulation of good news. As winners portfolios are with short-turn accumulation of good news, stock prices will raise and the returns will increase $(\triangle R$ increase). At the same time if loser portfolios are with short-turn accumulation of good news, stock prices will also raise and the returns will increase ( $\triangle \mathrm{L}$ increase). Compared with the return (S5-S1) of investment strategies of 3-week formation period and 3-week holding period is $0.69 \%$ in the Table 6 , We find that these returns are all higher than $0.69 \%$. It means that $\triangle R$ is bigger than $\triangle \mathrm{L}$. Therefore, we can conclude that the effects of short-turn accumulation of good news on winners are bigger than on losers. The upper-right of the table VII, including $(w n 1, \ln 4),(w n 1, \ln 5),(w n 2, \ln 4)$, and $(w n 2, \ln 5)$, represent winners portfolios with short-turn accumulation of good news but losers portfolios with short-turn accumulation of bad news. Since $\triangle \mathrm{R}$ increase but $\triangle \mathrm{L}$ decrease, (R-L) here should be higher. The results in the upper-right of the table VII support this argument.

\begin{tabular}{|c|c|c|c|c|c|}
\hline \multirow{2}{*}{$\begin{array}{l}\text { Investment } \\
\text { Strategy }\end{array}$} & \multicolumn{5}{|c|}{ Short Sell } \\
\hline & $\ln 1$ & $\ln 2$ & $\ln 3$ & $\ln 4$ & $\ln 5$ \\
\hline \multirow[t]{2}{*}{ wn1 } & -1.92 & -5.44 & -11.99 & -6.67 & 0.15 \\
\hline & $(-0.70)$ & $\left(-1.65^{*}\right)$ & $(-4.4 * * *)$ & $(-2.34 * *)$ & $(0.05)$ \\
\hline \multirow[t]{2}{*}{ wn2 } & -8.37 & -11.88 & -18.44 & -13.12 & -6.3 \\
\hline & $(-3.0 * * *)$ & $\left(-3.6^{* * *}\right)$ & $(-7.1 * * *)$ & $\left(-4.6^{* * *}\right)$ & $(-2.28 * *)$ \\
\hline \multirow{2}{*}{ Buy } & -0.01 & -3.52 & -10.08 & -4.76 & 2.06 \\
\hline & $(-0.00)$ & $(-1.10)$ & $\left(-4.1^{* * *}\right)$ & $(-1.74 *)$ & $(0.78)$ \\
\hline \multirow[t]{2}{*}{ wn4 } & -11.71 & -15.12 & -21.78 & -16.46 & -9.64 \\
\hline & $(-4.4 * * *)$ & $(-4.7 * * *)$ & $(-8.7 * * *)$ & $\left(-5.9^{* * *}\right)$ & $(-3.60 * * *)$ \\
\hline \multirow[t]{2}{*}{ wn5 } & -15.59 & -19.1 & -25.66 & -20.34 & -13.52 \\
\hline & $(-5.9 * * *)$ & $(-5.9 * * *)$ & $(-10.3 * * *)$ & $(-7.3 * * *)$ & $(-5.06 * * *)$ \\
\hline
\end{tabular}

Table VIII provides the connection between short-term accumulation of news and long-term sentiment momentum. As shown in Table VIII, the returns of sentiment momentum strategy in the whole table are all positive and mostly significant. Compared with Table VII, it means that long-term accumulation of news affects short-term sentiment momentum more apparently than long-term.

In addition, we notice that the returns of lower half of the table VII are higher than of upper half. This means that the stock prices of winners portfolios are under- estimated under the condition of long-term accumulation of bad news. Also, the returns of left half of the table VII are all positive. This result means that the stock prices of losers portfolios are over-estimated under the condition of long-term accumulation of bad news.

Table IX provides the connection between short-term accumulation of news and long-term sentiment momentum. As shown in Table IX, the returns in the bottom-left of the Table IX are all negative and mostly significant. The bottom-left of the table, including (wn4, $\ln 1)$, (wn4, $\ln 2)$, (wn5, $\ln 1)$, and $(w n 5, \ln 2)$, represent winners portfolios with long-turn accumulation of bad news but losers portfolios with long-turn accumulation of good news. Since $\triangle R$ decrease but $\triangle \mathrm{L}$ increase, (R-L) will decrease. Compared with the return (S5-S1) of investment strategies of 52-week formation period and 52 -week holding period is $-1.7 \%$ in the Table VI, we find that the returns in the bottom-left of the Table IX are all lower than $-1.7 \%$, the results are consistent with the argument above.

TABLE V: CONNECTION BETWEEN LONG-TERM ACCUMULATION OF News AND LONG-TeRm PRICE MOMENTUM

\begin{tabular}{|c|c|c|c|c|c|}
\hline \multirow{2}{*}{$\begin{array}{c}\text { Investment } \\
\text { Strategy }\end{array}$} & \multicolumn{5}{|c|}{ Short Sell } \\
\hline & $\ln 1$ & $\ln 2$ & $\ln 3$ & $\ln 4$ & $\ln 5$ \\
\hline \multirow[t]{2}{*}{ wn1 } & -6.99 & -5.83 & -14.53 & -16.66 & -15.93 \\
\hline & $\left(-2.9^{* * *}\right)$ & $\left(-2.4^{* * *}\right)$ & $(-6.00 * * *)$ & $\left(-5.5^{* * *}\right)$ & $(-5.7 * * *)$ \\
\hline \multirow[t]{2}{*}{ wn2 } & -4.4 & -3.53 & -12.23 & -14.36 & -13.63 \\
\hline & $\left(-1.8^{*}\right)$ & $(-1.38)$ & $(-4.82 * * *)$ & $\left(-4.6^{* * *}\right)$ & $(-4.7 * * *)$ \\
\hline \multirow{2}{*}{ Buy } & -3.08 & -2.22 & -10.92 & -13.05 & -12.31 \\
\hline & $(-1.31)$ & $(-0.90)$ & $(-4.47 * * *)$ & $(-4.3 * * *)$ & $\left(-4.4^{* * *}\right)$ \\
\hline \multirow[t]{2}{*}{ wn4 } & -14.52 & -13.66 & -22.36 & -24.49 & -23.76 \\
\hline & $(-5.7 * * *)$ & $(-5.1 * * *)$ & $(-8.47 * * *)$ & $(-7.7 * * *)$ & $\left(-7.9^{* * *}\right)$ \\
\hline \multirow[t]{2}{*}{ wn5 } & -11.33 & -10.47 & -19.17 & -21.3 & -20.56 \\
\hline & $(-4.1 * * *)$ & $(-3.7 * * *)$ & $(-6.80 * * *)$ & $\left(-6.4^{* * *}\right)$ & $\left(-6.5^{* * *}\right)$ \\
\hline
\end{tabular}

TABLE VI: SENTIMENT MOMENTUM

\begin{tabular}{|c|c|c|c|c|c|c|}
\hline \multirow{2}{*}{$\begin{array}{l}\text { Formation } \\
\text { Periods }\end{array}$} & \multirow{2}{*}{ Portfolios } & \multicolumn{5}{|c|}{ Holding Periods } \\
\hline & & 3 & 6 & 12 & 24 & 52 \\
\hline \multirow[t]{2}{*}{3} & S5-S1 & 0.69 & 0.77 & 0.93 & 0.22 & -0.12 \\
\hline & & $(1.67 *)$ & $(1.18)$ & $(0.92)$ & $(0.14)$ & $(-0.05)$ \\
\hline \multirow[t]{2}{*}{6} & S5-S1 & 0.61 & 0.55 & 0.35 & -0.26 & -0.09 \\
\hline & & $(1.46)$ & $(0.84)$ & $(0.33)$ & $(-0.16)$ & $(-0.04)$ \\
\hline \multirow[t]{2}{*}{12} & S5-S1 & 0.5 & 0.34 & 0.15 & -0.22 & 0.28 \\
\hline & & (1.19) & $(0.51)$ & $(0.15)$ & $(-0.13)$ & $(0.13)$ \\
\hline \multirow[t]{2}{*}{24} & S5-S1 & 0.22 & 0.09 & -0.13 & 0.18 & 0.56 \\
\hline & & $(0.51)$ & $(0.14)$ & $(-0.12)$ & $(0.11)$ & $(0.25)$ \\
\hline \multirow[t]{2}{*}{52} & S5-S1 & 0.28 & 0.23 & -0.15 & -0.45 & -1.7 \\
\hline & & $(0.67)$ & $(0.34)$ & $(-0.14)$ & $(-0.27)$ & $(-0.74)$ \\
\hline
\end{tabular}

Table $\mathrm{X}$ provides the connection between long-term accumulation of news and long-term sentiment momentum. As shown in Table $X$, the returns in the upper-right of the table $X$ are all negative and partly significant. The upper-right of the table, including (wn1, ln4), (wn1, ln5), (wn2, ln4), and (wn2, $\ln 5)$, represent winners portfolios with long-turn accumulation of good news but losers portfolios with long-turn accumulation of bad news. The stock prices of winners portfolios are over-estimated under the condition of long-term accumulation of good news and the stock prices of losers portfolios are under-estimated under the condition of 
long-term accumulation of bad news. Consequently, the whole returns (R-L) will decrease.

TABLE VII: CONNECTION BETWEEN SHORT-TERM ACCUMULATION OF NEWS AND SHORT-TERM SENTIMENT MOMENTUM

\begin{tabular}{|c|c|c|c|c|c|}
\hline \multirow{2}{*}{$\begin{array}{c}\text { Investment } \\
\text { Strategy }\end{array}$} & \multicolumn{5}{|c|}{ Short Sell } \\
\hline & $\ln 1$ & $\ln 2$ & $\ln 3$ & $\ln 4$ & $\ln 5$ \\
\hline \multirow{6}{*}{ Buy } & 0.76 & 0.9 & 0.4 & 1.31 & 1.23 \\
\hline & (1.56) & $\left(1.78^{*}\right)$ & $(0.87)$ & $\left(2.43^{* *}\right)$ & $\left(2.36^{* *}\right)$ \\
\hline & 1.08 & 1.22 & 0.72 & 1.63 & 1.55 \\
\hline & $(2.07 * *)$ & $(2.25 * *)$ & (1.45) & $(2.86 * * *)$ & $(2.79 * * *)$ \\
\hline & 1.38 & 1.52 & 1.02 & 1.93 & 1.85 \\
\hline & (3.03) & (3.19) & $(2.39 * *)$ & $(3.79 * * *)$ & $\left(3.76^{* * *}\right)$ \\
\hline \multirow[t]{2}{*}{ wn4 } & -0.09 & 0.05 & -0.45 & 0.46 & 0.38 \\
\hline & $(-0.16)$ & $(0.09)$ & $(-0.85)$ & $(0.78)$ & $(0.66)$ \\
\hline \multirow[t]{2}{*}{ wn5 } & 0.46 & 0.6 & 0.1 & 1.01 & 0.93 \\
\hline & $(0.91)$ & (1.14) & $(0.21)$ & $\left(1.82^{*}\right)$ & $\left(1.73^{*}\right)$ \\
\hline
\end{tabular}

Based on the results from Table VII to Table X, we can conclude that short-term sentiment momentum will be affected under the condition of both long-term and short-term accumulation of news but long-term sentiment momentum will not only be affected but also be reversed under the condition of both long-term and short-term accumulation of news.

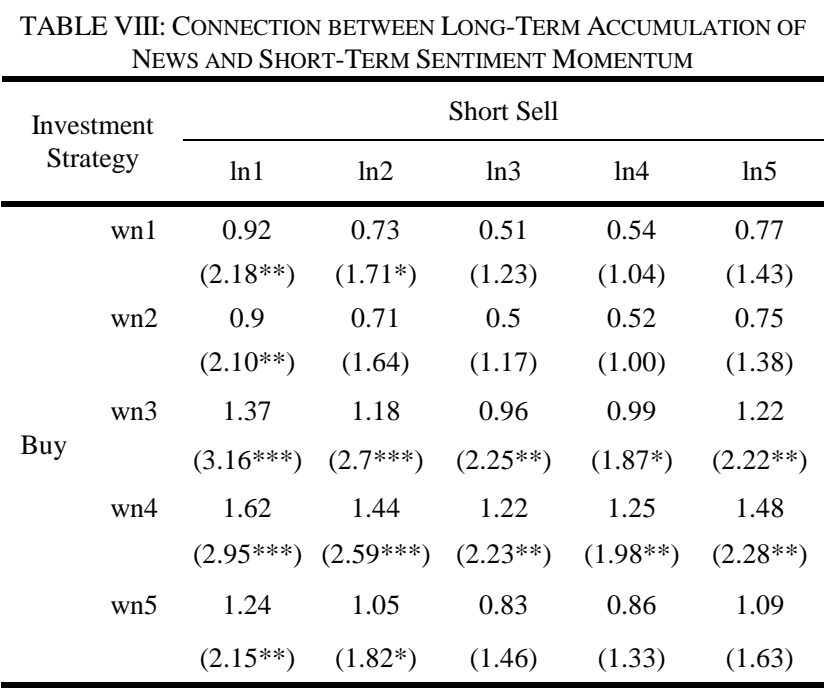

\section{CONCLUSION}

Using Taiwan Stock Exchange data from 2001 to 2010, the main purpose of this article is to investigate the different impact of long-turn from short-turn accumulation of news on price momentum and sentiment momentum. First, we find that there are short-term of price momentum and long-term price reverse in the Taiwan stock market. Then we collect all news of public listed companies and classify news into good news and bad news to study its effects on price momentum. The results show that short-turn accumulation of news will affect short-turn price momentum; its effect is more significant or reversed. That is to say, short-turn price momentum is easy to be affected by news about companies. On the other hand, long-term price reverse seem not to be affected by news about companies.

Second, we find that there is only short-term of sentiment momentum. Short-term sentiment momentum is affected by accumulation of news and more significant. However, though long-term sentiment momentum is not supported, but long-term sentiment momentum will be reversal and significant under the consideration of accumulation of news.

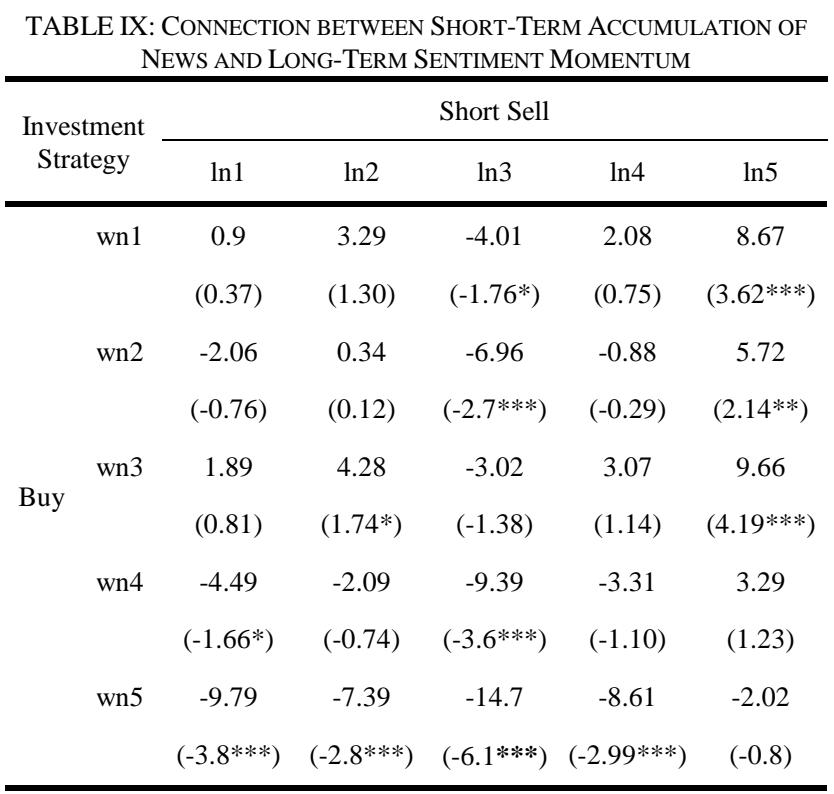

The implication of empirical results also indicate that investors can, in the short-run of accumulation of news, maximize their profit if they buy winners price momentum portfolios with no news and sell losers portfolios with bad news. Conversely, in the long-turm accumulation of news, investors should buy winners portfolios with bad news and sell losers portfolios with good news to maximize their profit in the short run.

TABLE X: CONNECTION BETWEEN LONG-TERM ACCUMULATION OF NEWS AND LONG-TERM SENTIMENT MOMENTUM

\begin{tabular}{|c|c|c|c|c|c|}
\hline \multirow{2}{*}{$\begin{array}{l}\text { Investment } \\
\text { Strategy }\end{array}$} & \multicolumn{5}{|c|}{ Short Sell } \\
\hline & $\ln 1$ & $\ln 2$ & $\ln 3$ & $\ln 4$ & $\ln 5$ \\
\hline \multirow{6}{*}{ Buy } & 0.39 & -1.17 & -6.93 & -1.96 & -6.62 \\
\hline & $(0.19)$ & $(-0.54)$ & $(-3.3 * * *)$ & $(-0.74)$ & $(-2.20 * *)$ \\
\hline & 1.15 & -0.41 & -6.17 & -1.19 & -5.86 \\
\hline & $(0.52)$ & $(-0.81)$ & $(-2.8 * * *)$ & $(-0.43)$ & $(-1.89 *)$ \\
\hline & 2.6 & 1.03. & -4.72 & 0.25 & -4.41 \\
\hline & $(1.25)$ & $(0.47)$ & $\left(-2.3^{* * *}\right)$ & (0.09) & $(-1.47)$ \\
\hline \multirow[t]{2}{*}{ wn4 } & 7.41 & 5.84 & 0.09 & 5.06 & 0.4 \\
\hline & $(2.51 * *)$ & $(1.93 *)$ & $(0.03)$ & $(1.50)$ & $(0.11)$ \\
\hline \multirow[t]{2}{*}{ wn5 } & 0.4 & -1.17 & -6.93 & -1.95 & -6.62 \\
\hline & $(0.17)$ & $(-0.47)$ & $(-2.9 * * *)$ & $(-0.67)$ & $(-2.05 * *)$ \\
\hline
\end{tabular}

This article is only a preliminary research; there is still space to be improved. For example, News about company in this research is from Market Observation Post System 
provided by Taiwan Stock Exchange Corporation. The row data is established by companies themselves. Other resource of proxy for good, bad news for companies may be necessary. Also, we only consider both holding periods and formation periods are 3 weeks as short-turn, and both holding periods and formation periods are 52 weeks as long-turn when discussing the effect of accumulation of news. More combination of holding periods and formation periods is helpful to confirm the conclusions.

\section{REFERENCES}

[1] E. F. Fama, "Efficient capital markets: A review of theory and empirical work," Journal of Finance, vol. 25, no. 2, pp. 383-417, 1970.

[2] W. F. DeBondt and R. H. Thaler, "Does the stock market overreaction?" Journal of Finance, vol. 40, no. 3, pp. 793-805, 1985.

[3] W. F. DeBondt, and R. H. Thaler, "Further evidence on investor overreaction and stock market seasonality," Journal of Finance, vol. 42, no. 3, pp. 557-581, 1987

[4] N. Jegadeesh and S. Titman, "Returns to buying winners and selling losers: Implications for stock market efficiency," Journal of Finance, vol. 48 , no. 1, pp. 65-91, 1993

[5] H. Shefrin, and M. Statman, "The disposition to sell winners too early and ride losers too long: Theory and evidence," Journal of Finance, vol. 40, no. 3, pp. 777-790, 1985.

[6] H. Shefrin, "Behavioral decision making, forecasting, game theory, and role-play," International Journal of Forecasting, vol. 18, no. 3, pp. 375-382, 2002

[7] J. P. Forgas, "Mood and judgment: The affect infusion model (AIM)," Psychological Bulletin, vol. 117, no. 1, pp. 39-66, 1995.

[8] G. H. Gendolla, "On the impact of mood on behavior: An integrative theory and a review," Review of General Psychology, vol. 4, no. 4, pp. 378-408, 2000.

[9] G. W. Brown and M. T. Cliff, "Investor sentiment and the near-term stock market," Journal of Empirical Finance, vol. 11, pp. 1-27, 2004

[10] M. Baker, and J. Wurgler, "Investor sentiment in the stock market," Journal of Economic Perspectives, vol. 21, pp. 129-151, 2007.

[11] M. Baker, and J. Wurgler, "Investor sentiment and the cross-section of stock returns," Journal of Finance, vol. 61, pp. 1645-1680, 2006.

[12] H. Hong, and J. C. Stein, "A unified theory of underreaction, momentum trading and overreaction in asset markets," Journal of Finance, vol. 54, no. 6, pp. 2143-2184, 1999.

[13] R. A. Levy, "Relative strength as a criterion for investment selection," Journal of Finance, vol. 22, no. 4, pp. 595-610, 1967.

[14] N. Barberis, A. Shleifer, and R. Vishny, "A model of investor sentiment," Journal of Financial Economics, vol. 49, pp. 307-343, 1998.

[15] A. Hameed, and Y. "Kusnadi, "Momentum strategies: Evidence from Pacific Basin stock markets," Journal of Financial Research, vol. 25 , no. 3, pp. 383-397, 2002.

[16] E. J. Johnson, and A. Tversky, "Affect, generalization, and the perception of risk," Journal of Personality and Social Psychology, vol. 45, no. 1, pp. 20-31, 1983.

[17] H. R. Arkes, L. T. Herren, and A. M. Isen, "The role of potential loss in the influence of affect on risk-taking behavior," Organizational
Behavior and Human Decision Processes, vol. 42, no. 2, pp.181-193, 1988.

[18] W. F. Wright, and G. H. Bower, "Mood effects on subjective probability assessment," Organizational Behavior and Human Decision Processes, vol. 52, no. 2, pp. 276-291, 1992.

[19] K. Daniel, D. Hirshleifer, and A. Subrahmanyam, "Investor psychology and security market underreaction and overreaction," Journal of Finance, vol. 53, no. 6, pp. 1839-1886, 1998.

[20] M. Baker, and J.C. Stein, "Market liquidity as a sentiment indicator," Journal of Financial Markets, vol. 7, pp. 271-299, 2004.

[21] P. Dennis, and S. Mayhew, "Risk-neutral skewness: Evidence from stock options," Journal of Financial and Quantitative Analysis, vol. 37, no. 3, pp. 471-493, 2002

[22] M. R. Randall, D. Y. Suk, and S. W. Tully, "Mutual fund cash flows and stock market Performance," Journal of Investing, vol. 12, no. 1, pp. 78-81, 2003

[23] M. Lashgari, "The role of TED spread and confidence index in explaining the behavior of stock prices," American Business Review, vol. 18, no. 2, pp. 9-11, 2000.

[24] M. S. Kumar, and A. Persaud, "Pure contagion and investors' shifting risk appetite: Analytical issues and empirical evidence," International Finance, vol. 5, no. 3, pp. 401-436, 2002.

[25] R. E. Whaley, "The investor fear gauge," Journal of Portfolio Management, vol. 26, no. 3, pp. 12-17, 2000

[26] A. Ljungqvist, V. Nanda, and R. Singh, "Hot markets, investor sentiment, and IPO pricing," Journal of Business, vol. 79, no. 4, pp 1667-1702, 2006.

[27] T. Odean, "Do investors trade too much?" American Economic Review, vol. 89, no. 5, pp. 1279-1298, 1999.

[28] A. V. Benos, "Aggressiveness and survival of overconfident traders," Journal of Financial Markets, vol. 1, pp. 353-383, 1998.

[29] J. S. Luo, and C. A. Li, "Futures market sentiment and institutional investor behavior in the spot market: The emerging market in Taiwan," Emerging Markets Finance and Trade, vol. 44, no. 2, pp. 70-86, 2008.

Shu-Ling Chang got her MBA in 1989 with major in international business from National Chengchi University, Taiwan. She is currently pursuing her $\mathrm{Ph} . \mathrm{D}$. from National Yunlin University of Science and Technology. She is also a lecture of Southern Taiwan University of Science and Technology in Taiwan at present.

Long-Jainn Hwang is currently an Associate Professor of Accounting at the Department of Marketing and Distribution Management of WuFeng University in Taiwan. He got his master degree of Mathematical Sciences in 1993 from State University of New York at Binghamton in USA and got his Ph.D. in 2015 with major in Accounting from National Chengchi University in Taiwan.

Chun-An Li is currently a Professor at the Department of Finance of National Yunlin University of Science and Technology in Taiwan. He got his Ph.D. with major in Accounting from National Chengchi University in Taiwan. Ph.D. in 2015 with major in Business Administration from National Chengchi University in Taiwan. His research interests include financial management and investment. 